\title{
Proceeding
}

Supplementary Issue: Winter Conferences of Sports Science. Costa Blanca Sports Science Events, 22-23 March 2021. Alicante, Spain.

\section{Effects of an 8-week intermittent aerobic training program on aerobic power in a professional soccer team}

\author{
GIUSEPPINA MIRANDA ${ }^{1}$, SARA ALIBERTI'1, PIETRO LUIGI INVERNIZZI² \\ ${ }^{1}$ University of Salerno, Italy \\ 2University of Milan, Italy
}

\begin{abstract}
Introduction Soccer is a very dynamic sport in which players must constantly adapt to game situations. As a result, the tension and effort during the game changes, depending on the action on the field. For this reason, aerobic power is a key element for a soccer player. Scope The objective is to test whether an 8-week intermittent training protocol can improve aerobic power in a professional soccer team. Methods The sample consisted of eighteen youth soccer players from a professional team with an average age of 17 years. For eight weeks, the players were subjected to intermittent training, i.e., running with variations in speed at predetermined times and distances: we proceeded with the principle of variation and progression of the load, up to week five, after which the intermittent work sessions were reduced to one per week. The reference parameter taken into consideration is the distance covered by the yo-yo intermittent recovery test, carried out before and after the training period. The Student's t-test for paired dependent samples was used as a statistical tool to verify the significance of the difference between the mean of the two tests. Results The result was statistically significant $(p<.05)$. Intermittent training was able to improve aerobic power in professional soccer team. Conclusion From the data obtained it is possible to evaluate the characteristics of the players to propose personalized loads or organize the work in small groups as homogeneous as possible to make the training more effective.
\end{abstract}

Keywords: Recovery; Soccer; Intermittent; Yo-yo test; Youth.

\section{Cite this article as:}

Miranda, G., Aliberti, S., \& Invernizzi, P.L. (2021). Effects of an 8-week intermittent aerobic training program on aerobic power in a professional soccer team. Journal of Human Sport and Exercise, 16(3proc), S1031-S1038. https://doi.org/10.14198/jhse.2021.16.Proc3.20

\section{Corresponding author. University of Salerno, Italy.}

E-mail: g.miranda18@studenti.unisa.it

Abstract submitted to: Winter Conferences of Sports Science. Costa Blanca Sports Science Events, 22-23 March 2021. Alicante, Spain.

JOURNAL OF HUMAN SPORT \& EXERCISE ISSN 1988-5202.

(c) Faculty of Education. University of Alicante.

doi:10.14198/jhse.2021.16.Proc3.20 


\section{INTRODUCTION}

Soccer is a very dynamic sport and it is the sport base for the epistemology of performance (Raiola, 2020ab); in which players must constantly adapt to the game situations. As a result, the tension and effort during the game changes, depending on the action on the field and the core and biomechanics and fast movement (D'Elia et al., 2020, Raiola et al., 2020). For this reason, aerobic power is a key element for a soccer player (Helgerud et al., 2001). It allows for improved recovery capacity (Izzo et al., 2020abc), especially after very intense efforts. Aerobic power is defined as the amount of oxygen that can be used by our body in the unit of time during progressive and increasing physical activity, until it is exhausted. It is closely related to heart rate, which can be derived in terms of heart beats per minute. An athlete's aerobic and anaerobic capacity can determine the outcome of competition (Rankovic et al., 2010; Vanderford et al., 2004) and therefore it is important to assess the athletes' ability within these areas. The player in the game is subject to periods of low intensity interspersed with periods of high intensity including standing, walking, running, and sprinting (Sannicandro et al., 2011) with frequent changes in direction (Stølen et al., 2005). During these peaks of intensity, the aerobic mechanism alone is not sufficient to cover the demand for energy, so the anaerobic mechanisms must intervene, which create immediate energy to meet the demand and allow to make available immediately to the muscles the amount of ATP needed. The body at this point is in debt of oxygen that must be repaid as soon as possible. Improving aerobic power is key to achieving this. Players need a high level of fitness to cope with the energy demands of the game. Training brings changes and adaptations to the body (Izzo et al., 2019ab). In the case of intermittent training, it results in improved endurance and strength. Aerobic and speed resistance training can be used during the season to improve high intensity intermittent exercise performance (Rampinini et al., 2007). Intermittent exercise results in improved VO2 max in athletes who already have good aerobic capacity, as it is a good training tool to maintain high levels of aerobic power (Gaetano \& Rago, 2014; Raiola \& D'Isanto, 2016). It is considered as an efficient training mode to improve the aerobic fitness of players during competitive season (Belegišanin, 2017). Therefore, it is important for players to develop their ability to perform repeated maximal, or near-maximal, efforts, which can be achieved through high-intensity, speed-resistance aerobic training (laia et al., 2009). Consequently, an intermittent training protocol with dedicated testing has been proposed to assess and improve players' ability to perform high-intensity activities during the game (Raiola \& Altavilla, 2020). The goal is to test whether an 8-week intermittent training protocol can improve aerobic power in a professional soccer team. For both a coach and an athlete, it is very important to periodically monitor the results of training programs (Ceruso et al., 2019; Raiola et al., 2018). For this, assessment tests are used in order to analyse the initial situation (Cirillo et al., 2016), plan and verify the results.

\section{METHODS}

\section{Study participants}

The sample consisted of eighteen youth soccer players from a professional team with an average age of 17 years. The inclusion criterion to be involved in the study was possession of a medical clearance at the beginning of the season to ensure that they were in good health. They underwent intermittent aerobic training to improve aerobic power.

\section{Study design}

The 8 weeks of work was divided into 2 parts: the first 4 weeks pre-season and from 5 onwards there was the start of the championship. The work carried out was based on an intermittent type of work, except in some sessions of the first weeks where it was also associated with a continuous varied work (running with speed variation) since the players were not yet conditioned. We proceeded with the principle of variation and 
progression of the load, up to week five after which the intermittent work sessions were reduced to one per week. The weekly work was carried out as follows:

\section{WEEK 1}

- MONDAY: 40' aerobic capacity: 2x15' (1'30":30").

- TUESDAY: 40' aerobic capacity: 2x20' (1'30":30").

- WEDNESDAY: aerobic power 4x1000.

- FRIDAY: aerobic power 4500 (450;600;750;900;750;600;450).

- SATURDAY: 2x6' (30":30") average speed: 16,8km/h (140metriin30") tot12' - average power 11.6 watts.

\section{WEEK 2}

- MONDAY: $5 \times 1000$ aerobic power.

- TUESDAY: 30' aerobic power: 3750m (150-300-450-600-450-300-150-450-600).

- THURSDAY: $3 \times 5^{\prime}$ (30":30") average speed 16.8km/h (140 $\mathrm{m}$ in 30") tot $15^{\prime}$ - average power 11.6 watts.

- SATURDAY: aerobic power (5400 m pyramid 600-500-400-300-400-500-600) + (600-500-400-300).

WEEK 3

- MONDAY: 2x8' running with speed variations: (70m sprint,32m rec,70m sprint,32 rec, $35 \mathrm{~m}$ sprint, $35 \mathrm{~m} \mathrm{rec}, 16 \mathrm{~m}$ sprint $16 \mathrm{~m}$ rec, $70 \mathrm{~m}$ sprint etc.).

- WEDNESDAY: $3 \times 6$ (30":25") vel $16.8 \mathrm{~km} / \mathrm{h}$ (140 $\mathrm{m}$ in 30") tot 20'-average power 12.6 watts.

- FRIDAY: 3x6'30" (25":25") speed $17.7 \mathrm{~km} / \mathrm{h}$ - (123 m in25") - tot 20'- average power 12.5 Wat.

\section{WEEK 4}

- MONDAY: 3x7' (25":25") speed $17.7 \mathrm{~km} / \mathrm{h}$ - (123m in 25") - tot $21^{\prime}$ - average power 12.5 Wat.

- THURSDAY: $3 \times 7^{\prime}$ (25":20") average speed $16.7 \mathrm{~km} / \mathrm{h}$ (116 $\mathrm{m}$ in 25") tot 21'-> average power 13.0 watts.

\section{WEEK 5}

- TUESDAY: 3x8' (20":20") average speed 18km / $\mathrm{h}(100 \mathrm{~m}$ in 20") tot24' - average power 13.2 watts.

WEEK 6

- TUESDAY: 3x6 'Shuttles $20 \mathrm{~m}+20 \mathrm{~m}+20 \mathrm{~m}$ (80m in 20":20" rec) -> average power 14 watts.

\section{WEEK 7}

- TUESDAY: 8' (15":15") average speed $18 \mathrm{~km} / \mathrm{h}(75 \mathrm{~m}$ in 15") + 6' (10":10") average speed $18 \mathrm{~km} / \mathrm{h}$ $\left(50 \mathrm{~m}\right.$ in $\left.15^{\prime \prime}\right)+6^{\prime}\left(10^{\prime \prime}\right.$ shuttle $25 \mathrm{~m}+25 \mathrm{~m}: 20$ " passive recovery).

\section{WEEK 8}

- TUESDAY: 8' (20" shuttle 50m + 50m :20" rec.) + 6' (15":15") + 4' (10":10") speed 18 km/h.

Athletes performed in and out the yo-yo intermittent recovery test. The Yo-yo test assesses an individual's ability to repeatedly perform intense exercise, specifically an individual's ability to recover from repeated exercise with a high level of contribution from the anaerobic system. Participants run and return on a $20 \mathrm{~m}$ course, with a 10-second active pause after every $40 \mathrm{~m}$, with speed increasing at set intervals until they are unable to continue. The test focuses on assessing the ability to perform intense drills and recover, which are essential components during intense periods of play. The first test was performed on 6/8/2019 and the second after 8 weeks of aerobic training on 8/10/2019. The reference parameter taken into consideration is the distance covered by the yo-yo intermittent recovery test, carried out before and after the training period. 


\section{Statistical analysis}

Before using the parametric tests, the assumption of normality was verified using the Shapiro-Wilk test. Next, the Student's t-test for paired dependent samples was used as a statistical tool to test for significance between the differences between the means of the two tests. The significance was set at $p<.05$.

\section{RESULTS}

The result is statistically significant $(p<.05)$. The players improved their performance in the yo-yo intermittent recovery test and consequently their aerobic power.

Table 1. Intermittent Recovery Test Pre e Post 8 weeks.

\begin{tabular}{lccc}
\hline Samples & Distance travelled $(\mathbf{m t}) \mathbf{0 6 / 0 8 / 2 0 1 9}$ & Distance travelled $(\mathbf{m t}) \mathbf{0 8 / 1 0 / 2 0 1 9}$ & Improvement in \% \\
\hline Athlete 1 & 2520 & 2720 & 7.9 \\
Athlete 2 & 2000 & 2440 & 22 \\
Athlete 3 & 2000 & 2400 & 20 \\
Athlete 4 & 1640 & 2360 & 43.9 \\
Athlete 5 & 2200 & 2320 & 5.5 \\
Athlete 6 & 1480 & 2320 & 56.8 \\
Athlete 7 & 1520 & 2200 & 44.7 \\
Athlete 8 & 1980 & 2120 & 7.1 \\
Athlete 9 & 1920 & 2080 & 8.3 \\
Athlete 10 & 1880 & 2080 & 10.6 \\
Athlete 11 & 1840 & 1960 & 6.5 \\
Athlete 12 & 1800 & 1920 & 6.7 \\
Athlete 13 & 1440 & 1880 & 30.6 \\
Athlete 14 & 1640 & 1880 & 14.6 \\
Athlete 15 & 1840 & 2120 & 15.2 \\
Athlete 16 & 1720 & 1760 & 2.3 \\
Athlete 17 & 1760 & 1960 & 11.4 \\
Athlete 18 & 1160 & 1520 & 31 \\
\hline
\end{tabular}

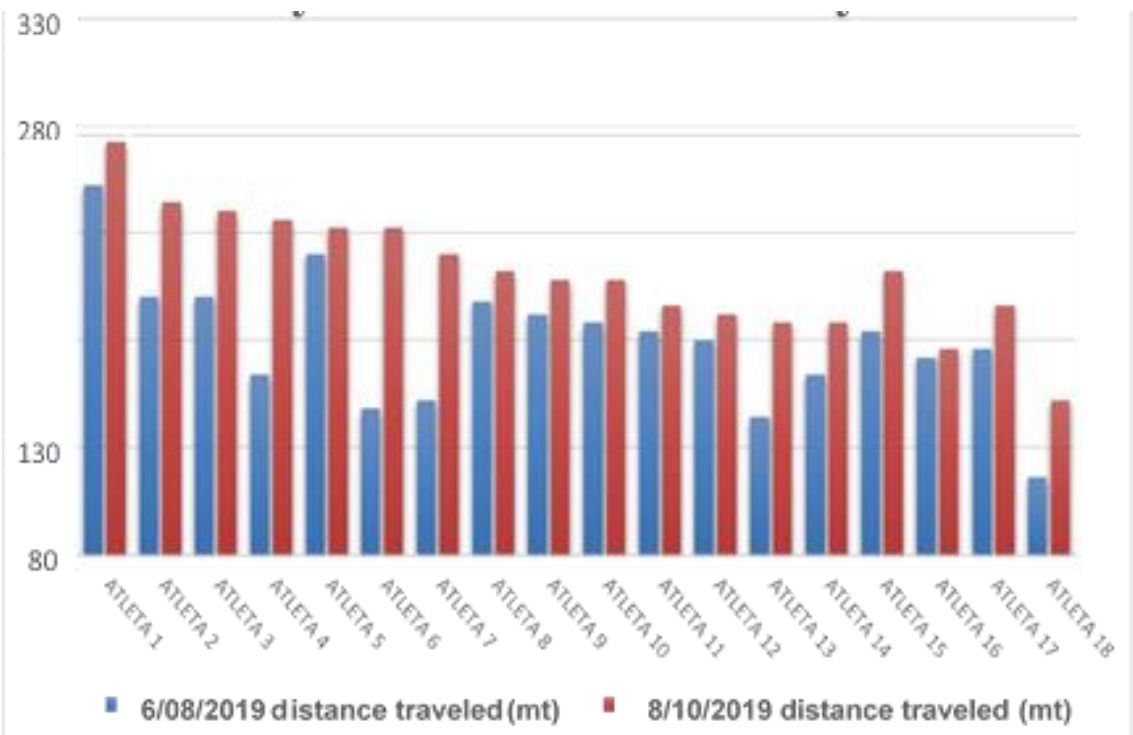

Figure 1. Graphic of intermittent recovery test pre and post 8 weeks. 
Table 2. T-test for paired dependent samples after 8 weeks.

\begin{tabular}{|c|c|c|c|c|c|c|c|c|c|}
\hline \multicolumn{10}{|c|}{ Paired Samples Test } \\
\hline & & \multicolumn{5}{|c|}{ Paired Differences } & \multirow{3}{*}{$\mathrm{t}$} & \multirow{3}{*}{ df } & \multirow{3}{*}{$\begin{array}{l}\text { Sig. (2- } \\
\text { tailed) }\end{array}$} \\
\hline & & \multirow[t]{2}{*}{ Mean } & \multirow[t]{2}{*}{$\begin{array}{l}\text { Std. } \\
\text { Deviation }\end{array}$} & \multirow[t]{2}{*}{$\begin{array}{l}\text { Std. Error } \\
\text { Mean }\end{array}$} & \multicolumn{2}{|c|}{$\begin{array}{l}95 \% \text { Confidence } \\
\text { Interval of the } \\
\text { Difference }\end{array}$} & & & \\
\hline & & & & & Lower & Upper & & & \\
\hline Pair 1 & $\begin{array}{l}\text { Pre - } \\
\text { Post }\end{array}$ & -316.66667 & 230.62575 & 54.35901 & -431.35415 & -201.97918 & -5.825 & 17 & .000 \\
\hline
\end{tabular}

\section{DISCUSSION}

Intermittent training was able to improve aerobic power in professional soccer team. From the values obtained from the yo-yo intermittent recovery test we note that the distance travelled in the second test increased from 8 weeks earlier with a statistically significant result (Tab 2). The literature suggests that aerobic capacity improves recovery from high intensity intermittent exercise through increased aerobic response, improved lactate removal, and improved PCr regeneration (Tomlin \& Wenger, 2001). In addition, intermittent training is useful for improving BMI and VO2max (Calandro et al., 2020). Aerobic power training is critical because it allows for improved recovery capacity, especially after very intense efforts. In other words, it allows the cardiac system to bring the frequency, in a short time, back to acceptable values. The description of the functional levels of strength capacity and aerobic power in youth categories allows selecting and determining the content of training, useful for the formation of the player and their future (Sannicandro et al., 2015). High aerobic power correlates with load during a competition and is said to aid recovery during intermittent high intensity exercises (Reilly, 1997). A professional soccer player is distinguished by taking into consideration his or her recovery time, which is necessary for the body to regain balance after prolonged exertion. One of the best ways to train it is undoubtedly the intermittent work, that is running with speed variations on predetermined times and distances. It is no coincidence that this is one of the most used types of training, especially for the resumption of training after the game. There is, however, another aspect to consider, which the playing position is. High intensity activity in elite soccer games is influenced by playing position (Bradley et al., 2009; Di Salvo et al., 2009). Each playing position is characterized by its own activity profile and different tactical demands in relation to ball movement (Altavilla et al., 2017). The percentage of improvement and distance covered depend on the role of the player. The distance is very different between players (Image 1) and this can be related to the position in a team (Bangsbo, 1994). Looking at the data (Tab 1), we can see that the highest initial value is from athlete 1 , who is a professional playing the role of an outside midfielder. However, the improvement was just $7.9 \%$, this is because he is well trained; in fact, the starting base is high. In addition, the distance covered by midfielders and fullbacks is high, with an average improvement of $21 \%$ and $7 \%$ respectively. According to one study, midfielders and full backs cover more distance than forwards and defenders in the intermittent recovery test (Mohr et al., 2003). This is because fullbacks and midfielders appear to perform more sprinting activities (Di Salvo et al., 2009). Wings, on the other hand, started from a lower base than the former and had a higher percentage of improvement. Defenders started from a low base. In fact, according to one study, central defenders cover less total distance and run at high intensity (Rampinini et al., 2007). Physical data is an indicator of performance but also the quality level of players (D'Isanto et al., 2020). Coaches should take into account these positional variations in distance travelled in order to design position-specific physical exercises (Rago et al., 2017). From the data obtained is to find the VAM (maximum aerobic speed), FC max, the threshold speed, necessary to propose organize the work in the best way. The VAM (Maximal Aerobic Speed) of the players can be identified through the speed maintained in the last step before the conclusion of the test. The VAM is the minimum speed at which VO2max is reached. Knowing the 
VAM, it will be possible to set the distances to be covered in the various proposals of intermittent type with changes of direction and meanings, but above all, it will allow dividing the team into different working groups according to VAM's results.

\section{CONCLUSION}

Intermittent training, performed for 8 weeks, has been shown to be effective in improving aerobic power in the professional football team in the football team. From the data obtained it is possible to evaluate the characteristics of the players, find their VAM, HR max and the threshold speed to propose personalized loads or organize the work in small groups as homogeneous as possible to make the training more effective. The player's role and position must also be taken into consideration, as each role needs specific programming.

\section{REFERENCES}

Altavilla, G., Riela, L., Tore, A. D., \& Raiola, G. (2017). The Physical Effort Required from Professional Football Players in Different Playing Positions. Journal of physical education and sport, 17, 20072012.

Bangsbo, J. (1994). The physiology of soccer--with special reference to intense intermittent exercise. Acta Physiol Scand Suppl, 619, 1-155.

Belegišanin, B. (2017). Effects of high-intensity interval training on aerobic fitness in elite Serbian soccer players. Exercise and Quality of Life, 9. https://doi.org/10.31382/eqol.171202

Bradley, P. S., Sheldon, W., Wooster, B., Olsen, P., Boanas, P., \& Krustrup, P. (2009). High-intensity running in English FA Premier League soccer matches. J Sports Sci, 27(2), 159-168. https://doi.org/10.1080/02640410802512775

Calandro, A., Esposito, G., \& Altavilla, G. (2020). Intermittent training and improvement of anthropometric parameters and aerobic capacity in youth football. https://doi.org/10.14198/jhse.2020.15.Proc3.12

Cataldi, S., Francavilla, V.C., Bonavolontà, V., De Florio, O., Carvutto, R., De Candia, M., Latino, F., Fischetti, F. (2021). Proposal for a fitness program in the school setting during the covid 19 pandemic: Effects of an 8-week crossfit program on psychophysical well-being in healthy adolescents. International Journal of Environmental Research and Public Health, 18 (6), art. no. 3141, pp. 1-12. https://doi.org/10.3390/ijerph18063141

Ceruso, R., Esposito, G., Federici, A., Valentini, M., \& D'Isanto, T. (2019). Preliminary work about the basis data for monitoring youth soccer team planning training (Vol. 14). https://doi.org/10.14198//hse.2019.14.Proc2.14

Cirillo, G., Nughes, E., Acanfora, A., Altavilla, G., \& D'Isanto, T. (2016). Physical and sport education testing by quantitative and qualitative tools in assessment in senior school: a proposal. Sport Science, 9(Suppl. 1), 97-101.

D'Elia, D., Domenico, F.D., Isanto, T.D., Altavilla, G., Raiola, G. (2020) From biomechanics to motor learning, Acta Medica Mediterranea, 36 (5), pp. 3073-3078.

Di Salvo, V., Gregson, W., Atkinson, G., Tordoff, P., \& Drust, B. (2009). Analysis of high intensity activity in Premier League soccer. Int J Sports Med, 30(3), 205-212. https://doi.org/10.1055/s-0028-1105950

Gaetano, R., \& Rago, V. (2014). Preliminary Study on Effects of Hiit-High Intensity Intermittent Training in Youth Soccer Players. Journal of physical education and sport, 14, 148-150.

Helgerud, J., Engen, L. C., Wisloff, U., \& Hoff, J. (2001). Aerobic endurance training improves soccer performance. Med Sci Sports Exerc, 33(11), 1925-1931. https://doi.org/10.1097/00005768$\underline{\text { 200111000-00019 }}$ 
laia, F., Rampinini, E., \& Bangsbo, J. (2009). High-Intensity Training in Football. International journal of sports physiology and performance, 4, 291-306. https://doi.org/10.1123/ijspp.4.3.291

Izzo, R., Cejudo, A., D'Isanto, T., Raiola, G., \& Giovannelli, M. (2020a). Performance Improvement in YoYo Intermittent Recovery Test Level 2 and During Official Matches: The Role of Speed Endurance Training Production in Élite Football Players. Montenegrin Journal of Sports Science and Medicine, 18. https://doi.org/10.26773/smj.201020

Izzo, R., D'Isanto, T., Raiola, G., Cejudo, A., Ponsano, N., Varde'i, C.H. (2020b) The role of fatigue in football matches, performance model analysis and evaluation during quarters using live global positioning system technology at 50hz, Sport Science, 13 (1), pp. 30-35.

Izzo, R., Giovannelli, M., \& D'Isanto, T. (2019). Original Article The injury prevention program WTA functional primitive movement in professional football players: A case study. Journal of physical education and sport, 19, 1885-1889. https://doi.org/10.7752/jpes.2019.s5279

Izzo, R., Giovannelli, M., \& Raiola, G. (2019). Training load in elite goalkeepers with K-Track for monitoring performance. Journal of physical education and sport, 19, 1890-1896. https://doi.org/10.7752/jpes.2019.s5280

Izzo, R., Raiola, G., D'Isanto, T., Cejudo, A., Giovanelli, G.M. (2020c) Modelling an adequate profile for a more targeted work methodology, with dedicated technologies, for elite-level footballers: Comparison between sub 17 vs sub 19, highlights and shadows, Sport Science, 13 (1), pp. 36-42.

Mohr, M., Krustrup, P., \& Bangsbo, J. (2003). Match performance of high-standard soccer players with special reference to development of fatigue. Journal of sports sciences, 21, 519-528. https://doi.org/10.1080/0264041031000071182

Rago, V., Pizzuto, F., \& Raiola, G. (2017). Relationship between intermittent endurance capacity and match performance according to the playing position in sub-19 professional male football players: Preliminary results. Journal of physical education and sport, 17, 688-691. https://doi.org/10.7752/jpes.2017.02103

Raiola, G. (2020a). Proposal of rearrangement of physical training and sport sciences methodology academic disciplines in Italian university body. Sport Science, 14 (1): 43-47.

Raiola, G. (2020b). The Movement and Sport Science in Italy towards the European Research Council. Physical Culture and Sport, Studies and Research, 86 (1): 37-48. https://doi.org/10.2478/pcssr-2020$\underline{0011}$

Raiola, G., \& Altavilla, G. (2020). Testing motor skills, general and special coordinative, in young soccer. https://doi.org/10.14198//hse.2020.15.Proc2.11

Raiola, G., Domenico, F.D., Isanto, T.D., Altavilla, G., Elia, F.D. (2020)Biomechanics core, Acta Medica Mediterranea, 36 (5), pp. 3079-3083.

Raiola, G. (2019) Comparison of exercise and sport sciences epistemology between european research council structure panel and Italian academic system, Sport Science, 12, pp. 112-120.

Raiola, G., D'Elia, F., \& Altavilla, G. (2018). Physical activity and sports sciences between European Research Council and academic disciplines in Italy (Vol. 13). https://doi.org/10.14198//hse.2018.13.Proc2.13

Raiola, G., \& D'Isanto, T. (2016). Assessment of periodization training in soccer. Journal of Human Sport and Exercise, 11. https://doi.org/10.14198/ihse.2016.11.Proc1.19

Rampinini, E., Coutts, A. J., Castagna, C., Sassi, R., \& Impellizzeri, F. M. (2007). Variation in top-level soccer match performance. Int J Sports Med, 28(12), 1018-1024. https://doi.org/10.1055/s-2007$\underline{965158}$

Rankovic, G., Mutavdzic, V., Toskic, D., Preljevic, A., Kocic, M., Nedin Rankovic, G., \& Damjanovic, N. (2010). Aerobic capacity as an indicator in different kinds of sports. Bosnian journal of basic medical sciences, 10(1), 44-48. https://doi.org/10.17305/bjbms.2010.2734 
Reilly, T. (1997). Energetics of high-intensity exercise (soccer) with particular reference to fatigue. J Sports Sci, 15(3), 257-263. https://doi.org/10.1080/026404197367263

Sannicandro, I., Piccinno, A., Rosa, R., \& Pascalis, S. (2011). Correlation between functional asymmetry of professional soccer players and sprint (Vol. 45). https://doi.org/10.1136/bjsm.2011.084038.171

Sannicandro, I., Spedicato, M., Palaia, G., Cofano, G., Bisciotti, G. N., \& Eirale, C. (2015). Strength ability, endurance and anthropometric parameters in youth football: Descriptive analysis and functional relationships. Medicina dello sport; rivista di fisiopatologia dello sport, 68, 19-30.

Stølen, T., Chamari, K., Castagna, C., \& Wisløff, U. (2005). Physiology of soccer: an update. Sports Med, 35(6), 501-536. https://doi.org/10.2165/00007256-200535060-00004

Tomlin, D. L., \& Wenger, H. A. (2001). The relationship between aerobic fitness and recovery from high intensity intermittent exercise. Sports Med, 31(1), 1-11. https://doi.org/10.2165/00007256200131010-00001

Vanderford, M., Meyers, M., Skelly, W., Stewart, C., \& Hamilton, K. (2004). Physiological and SportSpecific Skill Response of Olympic Youth Soccer Athletes. The Journal of Strength and Conditioning Research, 18, 334-342. https://doi.org/10.1519/R-11922.1

\section{@(@) $\Theta \Theta$}

This work is licensed under a Attribution-NonCommercial-NoDerivatives 4.0 International (CC BY-NC-ND 4.0). 